\title{
Recognition of and response to energy poverty in the United States
}

\author{
Dominic J. Bednar $₫$ and Tony G. Reames ${ }^{\circledR}$
}

\begin{abstract}
A household is energy poor when they cannot meet energy needs. Despite its prevalence, the US has not formally recognized energy poverty as a problem distinct from general poverty at the federal level, which limits effective responses. In this Review, we examine the measurement and evaluative metrics used by the two federally-funded energy programs focused on reducing high energy bills to understand how program eligibility requirements and congressional funding appropriations have shaped the national understanding and implementation of energy poverty assistance. We find that current measurement and evaluative metrics hinge on the distribution of government resources and the number of vulnerable households assisted, rather than improving household well-being and reducing overall energy poverty. We suggest that comparisons to formal food insecurity and fuel poverty recognition and national responses in the US and UK, respectively, can help inform the development of more comprehensive US responses to energy poverty going forward.
\end{abstract}

tark disparities exist in US energy burdens, the percentage of household income spent on energy bills. Urban and rural lowincome households (defined as $80 \%$ of area median income or $150 \%$ federal poverty level) spend roughly three times as much of their income on energy cost as compared to non-low-income households $(7.2 \% \text { and } 9 \% \text { versus } 2.3 \% \text { and } 3.1 \% \text {, respectively })^{1,2}$. Moreover, low-income, African American, Latinx, multifamily and renter households are disproportionately impacted by high energy burdens $^{1}$. Out of a total of 118.2 million US households, in 2015, the US Energy Information Administration (EIA) estimated that 17 million households received an energy disconnect/delivery stop notice and 25 million households had to forgo food and medicine to pay energy bills ${ }^{3}$. These household experiences have been described as indicators of energy insecurity or energy poverty-the inability of a household to meet their energy needs ${ }^{4}$. Yet, for the United States Government, energy insecurity and energy poverty are nebulous terms that do not exist in any statutory capacity. In other words, the federal government has not formally recognized energy poverty as a distinct problem.

In the absence of federal energy poverty recognition, states have implemented low-income energy assistance programs. Consequently, $51 \%$ of all funding to address high energy burdens is from utility ratepayer funded bill and energy efficiency assistance ${ }^{1}$. Despite the absence of federal statutes to characterize, measure and evaluate the landscape of and responses to energy poverty, the essence of this phenomenon has generally been recognized in the US as evidenced by two federally-funded energy assistance programs: the Low Income Home Energy Assistance Program (LIHEAP) and the Weatherization Assistance Program (WAP). LIHEAP and WAP are administered by two different federal agencies, the Department of Health and Human Services (DHHS) and the Department of Energy (DOE), respectively. These programs were created to combat rising energy costs and promote household energy sufficiency in response to the 1973 oil crisis ${ }^{5}$. However, after nearly fifty years of federal energy assistance, one in three US households (37 million), still experience energy poverty ${ }^{3}$.

While the UK and US have had similar responses to energy poverty reduction, one key area of divergence lies in their formal recognition. Notably, the UK's fuel poverty strategy formally recognizes households as fuel poor when incomes are lower than average and fuel costs are higher than average ${ }^{6}$. Despite a lack of data supporting precipitous reductions in fuel poverty, the UK is armed with pivotal information to aid a more rapid and adaptive response to fuel poverty exacerbated by the climate crisis ${ }^{7}$. Moreover, the requirements to systematically advance household energy efficiency by specific dates signals a united and national priority for overall household wellness and access achieved through the multiple benefits of energy efficiency ${ }^{8}$. Unlike the devolved UK nations ${ }^{8}$, the United States lacks federal energy poverty recognition and strategy that encompasses definitions, reduction targets/objectives and periodic evaluation.

In this Review, we suggest that the absence of formal energy poverty recognition at the federal level limits a more comprehensive understanding of and effective response to energy poverty as a distinct problem, and not simply a manifestation of more general problems of poverty. To this end, we describe energy poverty as the distinct notion of household energy deprivation that limits social and material necessities for participation in society ${ }^{9}$. We first review federal responses to energy poverty in the US as pseudo recognition. The energy poverty responses deployed by LIHEAP and WAP are used as case studies to describe how program eligibility requirements and congressional funding appropriations shape our understanding and targeting of which households require energy assistance. Then, we examine the performance measurements embedded within evaluative standards that indicate the program's success to demonstrate the misunderstanding of each program's effectiveness in reducing energy poverty. Next, we draw parallels to formal recognition and responses to food insecurity in the US, and to fuel poverty in England, as a way to promote a more expansive understanding of the current and future landscape of energy poverty and pathways to effectively responding in the US. We conclude with recommendations to advance national energy poverty reduction in the US, and in particular encourage the development and reassessment of an expansive energy poverty definition, reduction objectives, integrated strategies, and comprehensive measurement and evaluation. 


\section{US response to energy poverty as pseudo recognition}

Notwithstanding recognition short of a formal energy poverty definition, LIHEAP and WAP, alongside state level affordability targets and energy efficiency objectives serve as national responses to the issue. Government action at the intersection of energy and equity has been driven by either geopolitical or economic crises that affect energy prices, rather than by a comprehensive, long-term approach to address disparities in energy affordability. Energy poverty response as pseudo recognition has a nearly fifty-year history in the US beginning with the state of Maine's Office of Economic Opportunity initial recognition of the impact that the 1973 oil crisis had on low-income and elderly households' ability to meet their energy needs. In response, they applied for federal funds to implement 'Project Fuel'. Project Fuel's main focus was to weatherize homes; however, funds were also used for crisis counselling and purchasing fuel in emergency situations. Project Fuel inspired weatherization at the national level with a focus on household weatherization and energy conservation; additionally, funds were allowed for fuel voucher programs. The oil crisis catalysed a series of US government reorganizations and the creation of new energyrelated departments and programs, by which weatherization and household energy assistance became responses, or pseudo acknowledgements, of the issue of energy poverty. Figure 1 presents a timeline highlighting relevant policies associated with energy poverty responses, including the economic crisis of the late 2000s, which heightened government attention to low-income energy assistance programs and increased funding appropriations.

LIHEAP, authorized in 1981, provides home energy bill assistance to help subsidize high energy expenditures for low-income households. The WAP, authorized in 1976, is the largest and longest running federally-funded residential energy efficiency program. WAP provides eligible low-income families with the opportunity to permanently reduce onerous energy bills through cost-effective, energy efficiency upgrades. As a requirement, whole-house retrofit approaches are used to ensure the cost-effectiveness of energy efficiency measures. The whole-house approach guides energy efficiency measures by looking at the synergy of the building's envelope, appliances, and heating and cooling systems. Private contractors and in-house employees deliver weatherization services to WAP participating homes each year.

Program eligibility requirements, defined by statute and embedded within the purpose of both LIHEAP and WAP, identify which households are eligible for energy assistance and govern program targeting and implementation. Table 1 presents the LIHEAP and WAP program purpose, eligibility requirements and performance measures. Targeting approaches for WAP and LIHEAP are centred on income eligibility, a high energy burden, and demographic characteristics of a 'vulnerable household'. The statutes define vulnerable households as those with young children below five and elderly members above 65 years old, and individuals with disabilities. Eligibility based on household income maintains energy burden as the dominant metric to understand the prevalence and severity of US energy poverty.

LIHEAP and WAP are administered as block-grants by DHHS and DOE, respectively. Combined, the federal government has spent over US $\$ 134.6$ billion on low-income household energy assistance since the late 1970s. LIHEAP is a revenue support system provided to eligible households each year, whereas WAP is often a one-off, non-recurring capital investment in energy efficiency measures. LIHEAP benefits roughly 25 percent of eligible households each year and WAP has weatherized 7 million households; however, nearly 40 million households remain income-eligible for energy efficiency assistance ${ }^{10}$. Federal block-grants are provided to states, the District of Columbia, territories and Indian tribal organizations and are implemented at times, alongside utility ratepayer dollars at the household level by local governments or non-profit agencies, most often Community Action Agencies.
Program implementation is also shaped by annual congressional funding appropriations. For WAP, formula allocations for each state are based on three factors: low-income population as a share of the nation's total low-income population expressed as a percentage; climatic conditions obtained through heating and cooling degree days for each state; and, residential energy expenditures by low-income households in each state ${ }^{11}$. For LIHEAP, the funding formula is a bit more complicated and was updated in $1984^{12,13}$. Appropriations are released each year contingent on the formula and congressional Continuing Appropriation Resolutions. The previous formula of 1981 determined allocation percentages based on antiquated data, political compromise and accommodation $^{12}$. The 1984 'new' formula represents a percentage of US low-income energy expenditure by state. To capture state level low-income energy expenditure, the following values are used for household-level calculations: total residential energy consumed as measured by total British Thermal Units (Btu); temperature variation as 30-year average heating and cooling degree days; heating and cooling consumption for total US and low-income households; and average fuel price per fuel source.

Appropriations for these two programs have fluctuated over time, each receiving large boosts during the recession-era American Recovery and Reinvestment Act of 2009. It is important to note the historical disparity in their funding appropriations as shown in Fig. 2. LIHEAP funding averages nearly US $\$ 3$ billion annually since its inception. WAP funding pales in comparison to LIHEAP appropriations, averaging nearly US $\$ 0.4$ billion annually ${ }^{14}$. Comparatively, LIHEAP allows states to transfer up to $25 \%$ of its funds to WAP, making LIHEAP one of the largest additional potential funding sources for WAP. Even with greater funding, a majority of incomeeligible households (84\%) do not receive LIHEAP assistance ${ }^{10}$. Naturally, the immediate need of bill-assistance is greater than the speed at which households can be weatherized, warranting greater funds to LIHEAP. Nevertheless, the persistence of greater appropriations to LIHEAP over WAP appears to reflect a policy approach based on a notion that energy poverty is a temporary misfortune to be remedied primarily by some form of debt recovery, despite evidence demonstrating WAP as an effective and sustainable solution towards household energy affordability with multiple benefits ${ }^{15}$, including those to public health.

States have regulatory authority over LIHEAP and WAP implementation, and there are trends toward recognizing energy affordability as a policy priority at the state level. For instance, certain states have specific target dates to achieve energy efficiency objectives, such as Connecticut which aims to weatherize $80 \%$ of homes by 2030 (Public Act No. 11-80). Other states and municipalities have energy affordability goals. For example, the Governor of New York created an energy affordability policy in 2016 with a six percent energy burden goal and Portland, Oregon has a 10-year plan to reduce energy burdens in Oregon affordable housing. Moreover, several state-level energy regulatory requirements ensure lowincome energy assistance is provided in the form of energy efficiency and bill payment assistance to achieve energy affordability. State energy efficiency resource standards by law require utilities to pursue energy efficiency as a cost-effective energy resource ${ }^{16}$. Although eligibility requirements vary, utility ratepayer-funded programs often complement LIHEAP assistance and are funded through charges assessed on all or some commercial, industrial and residential customers. The assessed charges are often referred to as public goods surcharges, system benefits charges, public benefits, universal service fees, universal energy charges, or meter charges. State and local funds administered as supplements to LIHEAP funding garners eligibility for incentives from the federal government, thus increasing available resources to distribute. Additionally, on-bill financing programs are loans made to utility customers to pay for energy efficiency improvements. 
Oil crisis

Maine's 'Project Fuel'-first

federally-funded weatherization, crisis counselling and emergency fuel purchase program. Project Fuel became the basis for federal low-income weatherization.
Supplemental Appropriations Act (P.L. 95-26) First congressional funding appropriation (US\$200 million) helping low-income households (at or below $125 \%$ federal poverty level) pay energy bills through Special Crisis Intervention Program. Direct payments to fuel providers on behalf of low-income families made available by States.
Low Income Home Energy Act, Title XXV of the Omnibus Budget Reconciliation Act of 1981 (P.L. 97-35) Replaced LIEAP with present day, Low Income Home Energy Assistance Program (LIHEAP). Regardless of medical necessities, LIHEAP grantees could run cooling programs; offer weatherization; programs; offer weatherization; below $150 \%$ federal poverty level or $60 \%$ of state median income, whichever greater).

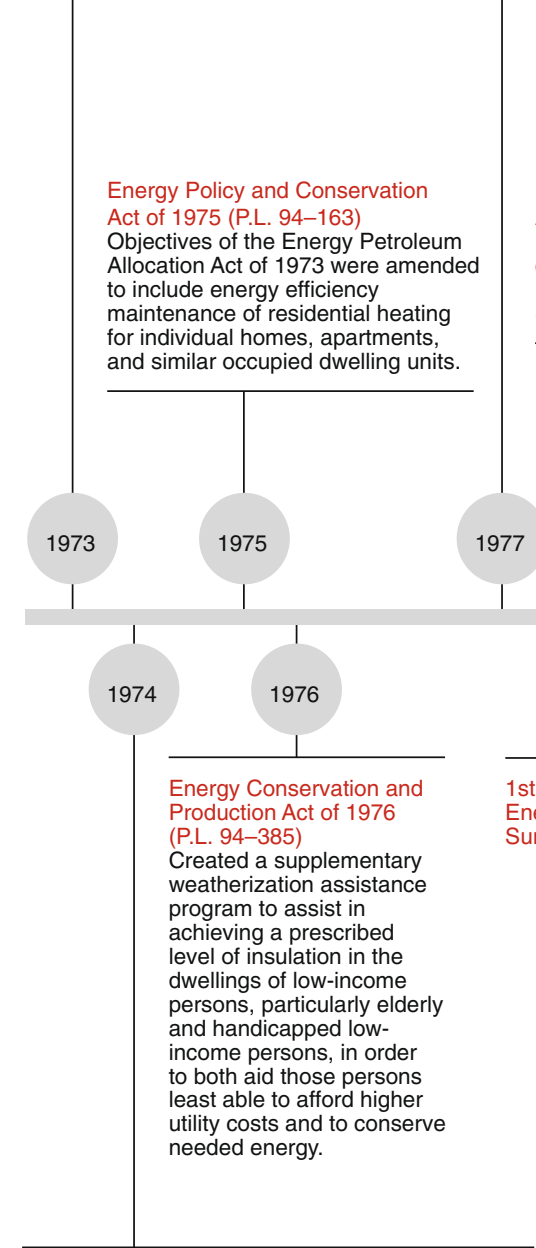

Headstart, Economic Opportunity and Community Partnership Act of 1974 (P.L. 93-644)

Created the Emergency Energy Conservation

Services program designed to enable low-income individuals and families, including the elderly and the near poor, to participate in energy conservation programs designed to lessen the impact of the high cost of energy and to reduce individual and family energy consumption. conducted under Emergency Energy Conservation Services program.
Government Performance and Results Act (GPRA) of 1993 (P.L. 103-62) Established a governmentwide requirement for federal agencies to develop performance goals and measures for federal programs.
Energy Policy Act of 2005 (P.L. 109-58)

Authorized states to purchase renewable fuels, including biomass, to implement the Low Income Home Energy Assistance programs. Instructed the Secretary of Health and Human Services to report to Congress on how LIHEAP could be used more effectively to prevent loss of life from extreme temperatures.

12th RECS Iteration

First inclusion of a set of questions that documented the different types of energy affordability problems that low-income households face; however, only LIHEAPqualified households within the sample were asked.

The American Recovery and

Reinvestment Act of 2009 (P.L. 111-5)

US $\$ 800$ billion recession-era economic stimulus package; increased WAP funding ( US $\$ 5$ billion); income eligibility revised (at or below $200 \%$ federal poverty level); 200,000 homes weatherized (2011-2012); included US $\$ 4.3$ billion in tax credits to homeowners for energy efficiency improvements.

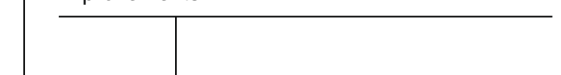
irst inclusion of questions documenting energy poverty experiences for all survey respondents.

Fig. 1 Timeline of US energy poverty response-as-recognition. Key developments in Public Law (P.L) and data aquistion between the years 1973 and 2015.

\section{Evaluation of US responses to energy poverty}

Performance measures and program evaluations are the lynchpins of federally funded energy assistance. They inform both the executive branch's and congressional committees' decision making about the programs they oversee ${ }^{17}$. The Government Performance and Results Act (GPRA) of 1993 emerged out of the 'frustration' that decision making was hindered by the shortage of good information on the results of federal program efforts ${ }^{17}$. Its update, the GPRA Modernization Act of 2010, reinforced key elements for improving the effectiveness and efficiency of government.
This Act emphasized the use of goals and measures to improve outcomes and requires quarterly review of progress achieved towards goals.

Performance goals/objectives are important because they guide performance measures that inform evaluations of program performance. Performance measures aim to provide quantifiable information on the effectiveness of meeting program performance goals/objectives. In other words, they help to evaluate the success of programs. Two organizations, APPRISE, Inc. (Applied Public Policy Research Institute for Study and Evaluation) and Oak Ridge 


\begin{tabular}{|c|c|c|}
\hline Program & LIHEAP & WAP \\
\hline Year created & 1981 & 1976 \\
\hline Administering agency & $\begin{array}{l}\text { US Department of Health and Human Services, Administration for Children } \\
\text { and Families, Office of Community Services, Division of Energy Assistance }\end{array}$ & $\begin{array}{l}\text { US Department of Energy, Office of } \\
\text { Energy Efficiency and Renewable Energy, } \\
\text { Weatherization and Intergovernmental } \\
\text { Programs Office }\end{array}$ \\
\hline Agency mission & $\begin{array}{l}\text { To enhance the health and well-being of Americans by providing effective } \\
\text { health and human services and by fostering medicine, public health and } \\
\text { social services }\end{array}$ & $\begin{array}{l}\text { To ensure America's security and prosperity } \\
\text { by addressing its energy, environmental and } \\
\text { nuclear challenges through transformative } \\
\text { science and technology solutions }\end{array}$ \\
\hline Purpose & $\begin{array}{l}\text { "to assist low-income households, particularly those with the lowest } \\
\text { incomes, that pay a high proportion of household income for home energy, } \\
\text { primarily in meeting their immediate home energy needs" }\end{array}$ & $\begin{array}{l}\text { "...to increase the energy efficiency of } \\
\text { dwellings owned or occupied by low-income } \\
\text { persons, reduce their total residential energy } \\
\text { expenditures, and improve their health } \\
\text { and safety, especially low-income persons } \\
\text { who are particularly vulnerable such as the } \\
\text { elderly, persons with disabilities, families } \\
\text { with children, high residential energy users } \\
\text { and households with high energy burden" }\end{array}$ \\
\hline Eligibility & $\begin{array}{l}\text { Highest value between a household: } \\
\text {-being at or below } 150 \% \text { of the federal poverty level (FPL) income guidelines; } \\
\text { or } \\
\text { - } 60 \text { percent of the state median income }\end{array}$ & $\begin{array}{l}-200 \% \text { FPL } \\
\text { - Recipient of Supplemental Security Income } \\
\text { or Aid to Families with Dependent Children } \\
\text { and less than } 200 \% \text { FPL (US DOE, 2017) }\end{array}$ \\
\hline
\end{tabular}

Performance measures Recipiency targeting Scores are the national percentage of LIHEAP-eligible $\begin{array}{ll}\text { Recipiency targeting } & \text { Scores are the national percentage of LIHEAP-eligible } \\ \text { index } & \text { households that receive services and have either a }\end{array}$ senior citizen or a young child (under the age of five) in the household, compared to the percentage of households estimated by the Census Bureau as being LIHEAP-income eligible and having a senior citizen or young child in the household

Energy burden measures

Benefit target index Does LIHEAP furnish higher benefits to higher burden households?

Burden reduction Does LIHEAP pay a larger share of the home energy target index bill for high burden households?

Prevention and restoration measures

Service loss How many times did a LIHEAP benefit prevent loss prevention of home energy services for households at imminent risk?

Service restoration How many times did a LIHEAP benefit restore home energy service for households who were disconnected, out of fuel or who had inoperable equipment?

Number of homes weatherized 


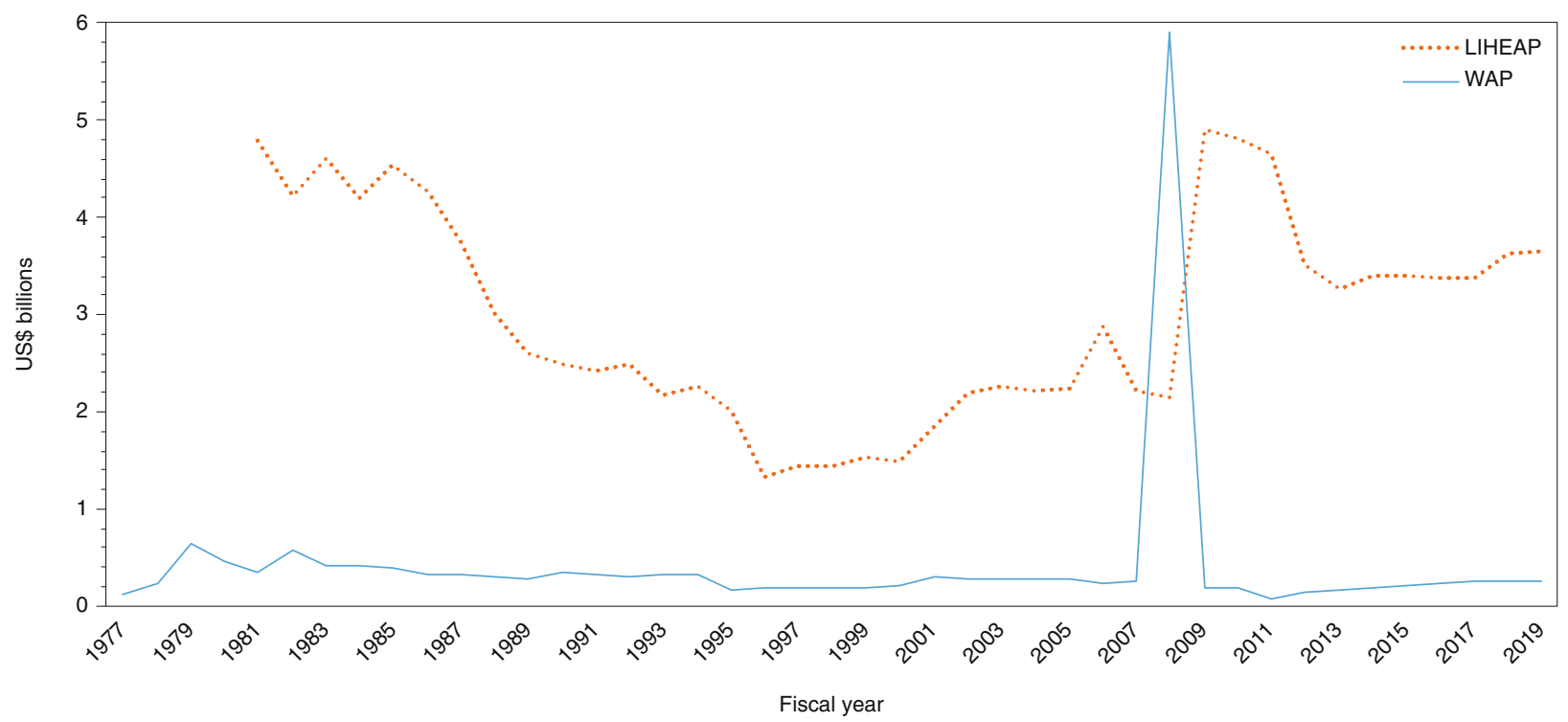

Fig. 2 | Historic LIHEAP and WAP funding appropriations by fiscal year. Values not adjusted for inflation. Shown in current US dollars. Figure data from LIHEAP Clearinghouse (https://liheapch.acf.hhs.gov/Funding/funding.htm).

Conversely, WAP has undergone several comprehensive national and local program evaluations since 1993 that assess the operations, cost-effectiveness and non-energy benefits of the implementation and benefits of $\mathrm{WAP}^{15}$. The peer-reviewed and statistically robust national evaluations have demonstrated that weatherization provides cost-effective energy savings, health and safety benefits, support for job creation, and a stable platform for continued investment in energy efficiency ${ }^{15,21}$. Specifically, WAP saves households an estimated average US $\$ 283$ annually alongside many other non-energy benefits ${ }^{21}$. Non-energy benefits garner US $\$ 2.78$ for every US $\$ 1.00$ invested into the program, providing more liveable homes, fewer missed days of work and decreased out-of-pocket medical expenses by an average of US $\$ 514$ annually $y^{21}$. Although these evaluations expand our understanding of the benefits of WAP, the primary performance measure that was used to demonstrate program success, similar to LIHEAP, can be classified as distributive or productionbased; specifically, the number of retrofits or low-income homes weatherized. Thus, performance measures have not appropriately assessed the effectiveness of energy efficiency improvements in solving the problem as outlined in the purpose of the established statute.

Although each program seeks to address the symptoms of energy poverty, the legislation creating each program did not formally recognize this problem. Consequently, reduction focused strategies or metrics embedded within a national energy poverty policy to understand the effectiveness of each program's response were not established. Nonetheless, each program has a list of successes, namely, reducing energy $\operatorname{costs}^{22,23}$, improving children's growth and health ${ }^{24}$, and reducing greenhouse gas emissions ${ }^{15,25}$. Despite measurable successes, without formal and comprehensive recognition of energy poverty, the effectiveness of current responses continues to be masked by poor performance measures not aligned with national energy poverty reduction.

This review of the LIHEAP and WAP program objectives and relevant policy documents juxtaposed to their fiscal imbalances reveals a dearth of definitions, measures and program evaluations that limit a more accurate characterization of the prevalence, severity and causes of energy poverty experienced in the United States.

\section{US recognition of and response to food insecurity}

In contrast to energy poverty, the prevalence and severity of other issues in the US have been recognized and understood more formally, namely, food insecurity. In 1990, the United States Department of Agriculture (USDA) formally established and endorsed a definition for food insecurity. The need for better monitoring and assessment of the nutritional state in the US led to the enactment of the National Nutrition Monitoring and Related Research (NNMRR) Act of 1990. Embedded within a 10-year comprehensive plan, the Act outlined a task to "recommend a standardized mechanism and instrument(s) for defining and obtaining data on the prevalence of 'food insecurity' or 'food insufficiency' in the United States and methodologies that can be used across the NNMRR program and at State and local levels"26.

To develop the needed measure, the federal interagency working group, the 'Food Security Measurement Project' was founded in 1992 and built on existing research, collaborating with the US Census Bureau and private-sector experts. The group ensured the final measure was appropriate and feasible for standard and consistent use across the country. Annual measurement began in 1995 by administering the food security questionnaire as a supplement to the current population survey. Initial analysis estimated the prevalence rates of food insecurity and produced a scale that measures the severity of deprivation in basic food needs as experienced across various household types. An assessment of the stability and robustness of the measurement model across years, major population groups and household types established the stability of the food security measure ${ }^{27}$. This type of federal recognition demonstrates the measurement capacity required to respond and reduce energy poverty in the US.

\section{UK recognition of and response to fuel poverty}

Rising energy costs during the 1973 oil crisis similarly affected UK households. This section highlights the ways in which the UK has recognized, responded to and evaluated fuel poverty as a way to encourage a more expansive understanding of the current and future landscape of energy poverty in the US.

Recognition. The UK became the first country in the world to formally recognize and strategically respond to fuel poverty. The Warm Homes and Energy Conservation Act of 2000 established a target for ending fuel poverty "as far as reasonably practicable" for all households within 15 years. This recognition prompted a legal commitment to produce a fuel poverty strategy; thus, elevating the urgency of the problem. Formal recognition provided an ambitious 
policy objective with outcomes that mattered at the household level. The strategy initially defined a fuel poor household as "...one which needs to spend more than $10 \%$ of its income on all fuel use and to heat its home to an adequate standard of warmth" ${ }^{28}$. Despite insufficient follow-through in practical policies, formal recognition embedded within the UK strategy provided the impetus for understanding the prevalence and severity of fuel poverty through measurement.

The established fuel poverty definition was complemented with an associated metric/measure that helped the UK nations to quantify household energy requirements against the strategy. The 'tenpercent indicator' catalysed national fuel poverty measurement. However, the fixed threshold made this definition hypersensitive to changes in domestic energy costs and made it more difficult to track the impact of implemented response measures that improved energy efficiency ${ }^{29}$, thus concealing the impact experienced at the household level, rendering the metric invalid.

The critiques of this definition and metric led to the English adoption of the Low Income High Cost (LIHC) metric in the updated 2015 fuel poverty strategy ${ }^{6}$. The LIHC measure identifies fuel-poor households as those where incomes are lower than average and fuel costs are higher than average. This updated metric enabled better targeting and prioritization of English households living in the most severe cases of fuel poverty. However, the devolved nations retain the ten percent indicator. Notwithstanding the capacity of the LIHC metric to identify fuel-poor households, its relative nature is critiqued because it allows households to move in and out of fuel poverty ${ }^{30}$ and obscures the role energy markets play in creating fuel poverty ${ }^{31}$.

Subsequently, the proposed Low Income Low Energy Efficiency (LILEE) metric aims to broaden and update the current measure to an absolute measure-capturing all low-income households with high costs that live in inefficient homes ${ }^{30}$. The proposed measure identifies households as fuel poor if they live in property with an energy efficiency rating below band $\mathrm{C}$ per the Fuel Poverty Energy Efficiency Rating (FPEER) system and, if after housing costs and energy needs, their income would be below the poverty line ${ }^{30}$. Based on the government's Standard Assessment Procedure, FPEER assesses the energy performance of domestic properties while accounting for the direct impact policy interventions have on household energy costs ${ }^{32}$. The current high cost threshold would change to an absolute one while the income threshold remains unchanged per existing LIHC methodology. This metric is better aligned with the statutory fuel poverty targets described in the next two sections, Response and Evaluation. The formal recognition of fuel poverty in the UK as a distinct problem, separate from general poverty, has allowed for an adaptive understanding of the problem's manifestation over time.

Response. Throughout the history of fuel poverty responses in the UK, household energy efficiency improvements were maintained as the primary and most cost-effective vehicle to address the negative impacts on health and well-being associated with living in a cold home. For example, from 2000 to 2013, England's Warm Front Home Energy Efficiency Scheme (WF) lessened the prevalence of fuel poverty whilst cutting greenhouse gas emissions and increasing household annual income ${ }^{33}$.

Key fuel poverty policies centre on the implementation of energy efficiency for households. Expressively, this technical conception has been critiqued as potentially damaging, marginalizing other solutions towards income and living cost equality ${ }^{31}$. Even so, the 2014 statutory fuel poverty target for England echoes energy efficiency as the primary method and commits to ensuring that as many fuel poor households as reasonably practicable achieve a minimum FPEER rating by $2030^{6}$ with interim targets by 2020 and 2025. The 2015 strategy ${ }^{6}$ in England emphasized more effective policy-making and delivery to address the structural problems of fuel poverty and to meet decarbonization goals. To tackle the least energy-efficient private rental properties in England and Wales, the Minimum Energy
Efficiency Standards established a baseline efficiency for new and renewal tenancies based on FPEER. Coordination efforts between relevant health and housing policies with other departments initially hampered the implementation of energy efficiency assistance (WF) to households suffering the most. Since the demise of WF, no government funding is provided for energy efficiency. However, similar to on-bill financing schemes, the Green Deal supports energy efficiency through a pay-as-you-save private loan scheme for household energy efficiency upgrades ${ }^{33}$. The Energy Company Obligation (ECO) is an energy efficiency scheme in the UK aimed to tackle fuel poverty. The ECO levies money from each customer as a proportion of their bill, so all income groups contribute payments. The fund is then spent on energy efficiency improvements in people's homes. ECO is meant to be focused primarily on the fuel poor; however, the poor definition of eligibility limits effective targeting.

Evaluation. The annual fuel poverty statistics monitor progress against the 2015 statutory target and track (1) the proportion of households in fuel poverty using the LIHC indicator and (2) their fuel poverty gap, that is the reduction in fuel bill that the average fuel poor household needs in order to not be classified as fuel poor ${ }^{34}$. These headline statistics are based on data collected by the English Housing Survey, a continuous national survey commissioned by the Ministry of Housing, Communities and Local Government and provides information about the housing circumstances, condition and energy efficiency of English homes. These data are vital elements that support England's Department for Business, Energy \& Industrial Strategy (BEIS) to develop, monitor and evaluate the key fuel poverty policies ${ }^{6}$. To measure progress against the 2014 fuel poverty targets, BEIS is legally bound to use FPEER ${ }^{32}$. The Committee on Fuel Poverty (formally the Fuel Poverty Advisory Group) is a non-departmental public body sponsored by BEIS established to monitor the English Government's progress on the 2015 fuel poverty strategy and to provide independent, expert guidance on meeting milestones and targets ${ }^{6,35}$. The UK's fuel poverty evaluation approach provides the mechanisms to track policy goals with embedded public oversight to ensure the government is meeting those goals.

\section{Moving Forward}

There is an opportunity to explore the benefits demonstrated by UK fuel poverty and US food insecurity recognition, responses and evaluation. Notably, formal recognition of US energy poverty would catalyse rapid energy efficiency investments, develop universal metrics to understand the landscape of US energy poverty and align LIHEAP and WAP statutes with associated health outcome/impact performance measures.

To move towards a more nuanced understanding of and efficient response to energy poverty reduction, we suggest a more inclusive and efficient inquiry to energy poverty engagement that establishes the prevalence and severity of energy poverty experienced across the US, explores its drivers, determines reasonable energy poverty reduction objectives, investigates how existing policy and programs compliment and coordinate innovative solutions to achieve set objectives, evaluates the effectiveness of deployed solutions and assesses how such solutions may be optimized for climate adaptation. Ultimately, we hope that this leads to the establishment of a statutory amendment that tasks the development of an independent interagency working group and a national energy poverty strategy including a definition and comprehensive measurement and evaluation of local, state, and national progress towards set reduction objectives in the United States.

The development of an energy poverty strategy, including definition, metrics and solutions must be reflected in the principles of risk assessment. Failing to acknowledge the risk or potential harm that may occur with living in sub-standard housing, or lack of household 
energy, should be regarded as a threat to national well-being and potential to rival other nations and spur economic growth. In recognizing the risks to public health vis-à-vis household energy poverty ${ }^{4,36}$, risk characterization provides a lens that encourages energy poverty problem formulation. Risk characterization accurately describes hazardous situations in a way that reflects the significant concerns of the interested and affected parties ${ }^{37}$. This decisionrelevant description should be understood and accessible to the parties and pubic officials ${ }^{37}$. The usefulness of risk characterization and subsequent risk analysis will fail if the perspectives and knowledge of the interested and affected parties are absent ${ }^{37,38}$. Applying the techniques of risk analysis and characterization are essential in making informed decisions on human health, welfare and the environment as linked to energy poverty.

Problem characterization and solution interventions should employ an energy vulnerability perspective. Energy vulnerability recognizes the multidimensionality of household energy poverty and offers a new lens to characterize the problem spatially and temporally whilst seeking understanding of the dynamics that influence a household's energy poverty risk. Through this lens, energy poverty is recognized as a 'state' within a certain temporal frame and identifies vulnerability as a set of conditions leading to such circumstances in that state ${ }^{39}$. Thus, energy vulnerability thinking can be seen as probabilistic, highlighting the factors that influence the likelihood of becoming energy poor ${ }^{39}$. Correspondingly, a consistent, comprehensive definition of energy poverty centred on the notion of energy vulnerability is vital to formally recognize energy poverty and bridge the assessment gap between scholars, policymakers and program managers. Thus, we propose to define US energy poverty as a state where households are challenged by everyday situations in meeting basic energy needs because of an assemblage of socio-economic, technical and environmental-political factors ${ }^{4,40,41}$. Factors known to be associated with energy poverty include gender, age, housing age, tenure type, energy inefficiency, education, employment, geography, socioeconomic status and race/ethnicity ${ }^{42-44}$.

Given the multidimensionality and variation of energy poverty regionally $y^{1,2,44}$, the production of data that characterizes this problem for the US should be intentional in its exploration. Thus, the development of quality indicators and data sets would aid capturing the essence of this problem beyond existing energy affordability measures. A standardized national instrument developed in concert with an independent, interagency working group is critical to understand the landscapes of energy poverty temporally.

Equipped with the capability to measure different dimensions of energy poverty, reasonable reduction-based objectives surface as an opportunity for local development and national coordination. Objectives establish baseline goals through which energy poverty reduction can be assessed and achieved. Formal energy poverty recognition alongside reduction-based objectives and performance measures would better align LIHEAP and WAP as an official energy poverty strategy that encourages longitudinal data collection and innovative solutions.

The separate federal channels for LIHEAP and WAP limit opportunities for coordination, promote redundant administrative and reporting duties for states and local agencies, and maintain incompatible eligibility requirements. We envision a restructuring that collapses the processes and procedures of LIHEAP and WAP under the DOE given their demonstrated measurement and evaluative efforts and WAP's more expansive statutory purpose. Such restructuring would require a good database ${ }^{7}$ and would promote alignment of broader public health ${ }^{4}$ and carbon mitigation goals with interim targets for energy poverty elimination by 2030 and 2050 .

Energy efficiency evaluation, measurement and verification are vital in demonstrating the financial benefits of bill assistance and the multiple benefits of energy efficiency ${ }^{45}$. Reduction focused performance measures and program evaluations offer a means to incorporate existing WAP evaluation components aimed at minimizing environmental and health risks, whilst maximizing energy and cost savings. Periodic evaluation would maintain a record of the effectiveness of deployed responses. Energy poverty and its responses can then be reassessed to understand how the landscape has changed and how the problem of energy poverty has evolved.

\section{Conclusions}

We contend that the absence of formal energy poverty recognition at the federal level has limited a more precise response and more inclusive understanding of the prevalence, severity and causes of energy poverty in the US. Issues of energy poverty remain omnipresent across the US despite the presence of local, state and federally funded energy assistance programs for energy burden reduction. Historically, the US has entrenched its assessment and response to energy poverty through national programs based on low household incomes and relative energy burdens, which has constrained the understanding and targeting potential of energy poverty exclusively towards affordability and away from related health outcomes as a result of household inefficiencies.

Congressional funding appropriations showcase the primary response and disproportionate support that LIHEAP historically receives compared to WAP and elucidate the disparity in investments of federal resources aimed at responding to energy poverty, despite LIHEAP's design as a short-term solution. We do not highlight the disparities in congressional funding as a means to bolster support for its discontinuation or disinvestment. Rather, these disparities magnify the need for purposeful performance measures and systematic program evaluations that underpin the process in funding federal energy assistance programs.

Current performance measures and program evaluations hinge on distributive targets-focusing on the number of households assisted. The consequences of distributive focused performance measures are a product of mis-characterizing US energy poverty and a quotient of its evaluation history, and suggest the inadequacies of LIHEAP to holistically ensure the reliability of adequate household energy services alone. Without appropriate performance measures to aid the evaluation of household energy poverty reduction and health improvement, near and far term understandings of energy poverty reduction and responses will remain insufficient.

Moving forward, a statutory amendment is needed that defines energy poverty, promotes its reduction and develops performance measures to more inclusively understand and evaluate the impact of all energy poverty responses. Energy vulnerability thinking can connect the analysis of inequities in vulnerability to household energy poverty. This perspective maintains the significant role data driven evaluation, measurement and verification of outcomes have on minimizing environmental and health risks whilst maximizing energy and cost savings. Energy vulnerability framing in concert with energy ${ }^{46,47}$ and environmental justice ${ }^{48}$ principles amplify the need for adequate access to affordable household energy and the need to recognize its importance as a national policy issue. This reframing prompts a research agenda and policy action to ameliorate US energy poverty.

To solve the multidimensional issues of energy poverty, the US must develop an expansive framework and respond with clarity. Fortunately, there is an opportunity to tackle energy poverty, which is being exacerbated by climate change and unjust energy transitions, by leveraging the history, shortfalls and innovation of formal fuel poverty recognition and responses in the UK. The preponderance of household energy inequities that plague low-income and households of colour will intensify if the realities of energy poverty in the US are not first acknowledged.

Received: 12 September 2019; Accepted: 14 February 2020; Published online: 23 March 2020 


\section{References}

1. Drehobl, A. \& Ross L. Lifting The High Energy Burden In America's Largest Cities: How Energy Efficiency Can Improve Low Income And Underserved Communities (American Council for an Energy-Efficient Economy, Energy Efficiency for All, 2016); https://www.energyefficiencyforall.org/resources/ lifting-the-high-energy-burden-in-americas-largest-cities-how-energy/ This study estimates energy burden in the largest US cities and finds that low-income households have an energy burden twice the median household energy burden.

2. Ross, L., Drehobl, A. \& Stickles, B. The High Cost of Energy in Rural America: Household Energy Burdens and Opportunities for Energy Efficiency (American Council for an Energy Efficient Economy, 2018).

3. 2015 Residential Energy Consumption Survey (RECS) (US Energy Information Administration, 2018)

4. Hernández, D. Understanding 'energy insecurity' and why it matters to health. Social Science \&. Medicine 167, 1-10 (2016).

Defines energy insecurity as a three-dimensional construct marked by the interplay between economic, physical and behavioural factors.

5. Higgins, L. \& Lutzenhiser, L. Ceremonial equity: low-income energy assistance and the failure of socio-environmental policy. Soc. Prob. 42, 468-492 (1995). Identifies persistent inequalities in the distribution of energy assistance benefits.

6. Cutting the Cost Of Keeping Warm: A Fuel Poverty Strategy For England URN 15D/062 (HM Government, 2015).

7. Dobbins, A., Nerini, F. F., Deane, P. \& Pye, S. Strengthening the EU response to energy poverty. Nat. Energy 4, (2019).

8. Thomson, H., Snell, C. J. \& Liddell, C. Fuel poverty in the European Union: a concept in need of definition?. People Place \& Policy 10, 5-24 (2016).

9. Bouzarovski, S. in Energy Poverty 1-8 (Palgrave Macmillan, 2018).

10. LIHEAP Report to Congress (RTC) for Fiscal Year (2014) (US Department of Health and Human Services, 2014).

11. Sissine, F. J. DOE Weatherization Program: A Review of Funding, Performance and Cost-Effectiveness Studies (Congressional Research Service, 2012). A report on the Weatherization Assistance Program's funding, evolution, assessments and benefit-cost evaluations.

12. Kaiser, M. J. \& Pulsipher, A. G. Science and politics: The 1981 and 1984 LIHEAP distribution formulas. Socioecon. Plann. Sci. 40, 15-51 (2006).

13. Perl, L. The LIHEAP Formula (Congressional Research Service, 2015).

14. 2018 Second Release of LIHEAP Block Grant Funds to States and Territories under the Consolidated Appropriations Act, 2018 (P.L. 115-141) (LIHEAP Clearing House, accessed 27 December 2019); https://liheapch.acf.hhs.gov/ Funding/funding.htm

15. Tonn, B. et al. Weatherization Works II - Summary of Findings from the ARRA Period Evaluation of the US Department of Energy's Weatherization Assistance Program (Oak Ridge National Laboratory, 2015).

16. Reames, T. G., Stacey, M. B. \& Zimmerman, M. A Multi-State Analysis of Equity in Utility-Sponsored Energy Efficiency Investments for Residential Electric Customers (Urban Energy Justice Lab and UM Poverty Solutions, 2019). A study that assessed distributional disparities in utility-funded residential energy efficiency program investments in the US.

17. Performance Measurement and Evaluation: Definition and Relationships (US Government Accountability Office, 2011).

18. Report to Congress (RTC) for Fiscal Year (2015) (US Department of Health and Human Services, 2015).

19. LIHEAP Energy Burden Evaluation Study (Apprise, 2005).

20. Annual Performance Plan and Report. Fiscal Year 2017 (US Department of Health and Human Services, 2016).

21. Weatherization Assistance Program. National Evaluations: Summary of Results (US DOE, 2015); https://weatherization.ornl.gov/wp-content/ uploads/2018/06/WAPNationalEvaluationWxWorksv14blue8515.pdf Data derived from the Retrospective Evaluation of Program Year 2008 that is reflective of a typical year in WAP operations.

22. LIHEAP Home Energy Notebook for FY 2014 (US Department of Health and Human Services, 2016)

23. Murray, A. G. \& Mills, B. F. The impact of low-income home energy assistance program participation on household energy insecurity. Contemp. Econ. Policy 32, 811-825 (2014).

24. Frank, D. A. et al. Heat or eat: The Low-Income Home Energy Assistance Program and nutritional and health risks among children less than 3 years of age. Pediatrics 118, e1293-e1302 (2006).

25. Eisenberg, J. Weatherization Assistance Program Technical Memorandum Background Data and Statistics on Low-Income Energy Use and Burdens. Oak Ridge National Laboratory ORNL/TM-2014/133 (Oak Ridge National Laboratory, 2014).

26. Ohls, J., Radbill, L. \& Schirm, A. Household Food Security in The United States, 1995-1997: Technical Issues and Statistical Report (Mathematica Policy Research, 2001).
27. Bickel, G., Nord, M., Price, C., Hamilton, W. \& Cook, J. Guide to measuring household food security (United States Department of Agriculture, 2000).

28. The UK Fuel Poverty Strategy (Department for the Environment Food and Rural Affairs and Department of Trade and Industry, 2001).

29. Hills, J. Getting the Measure of Fuel Poverty: Final Report of the Fuel Poverty Review CASE report 72 (Centre for Analysis of Social Exclusion, 2012).

30. Consultation on Fuel Poverty Strategy (Department for Business, Energy \& Industrial Strategy, 2019).

31. Middlemiss, L. A critical analysis of the new politics of fuel poverty in England. Criti. Soc. Policy 37, 425-443 (2017).

32. Fuel Poverty Energy Efficiency Rating Methodology URN 14D/273 (Department of Energy and Climate Change, 2014).

33. Sovacool, B. K. Fuel poverty, affordability, and energy justice in England: Policy insights from the Warm Front Program. Energy 93, 361-371 (2015).

34. Annual Fuel Poverty Statistics Report (Department for Business, Energy \& Industrial Strategy, 2019).

35. Committee on Fuel Poverty Third Annual Report (Committee on Fuel Poverty, 2018)

36. Liddell, C. \& Morris, C. Fuel poverty and human health: a review of recent evidence. Energy Policy 38, 2987-2997 (2010).

37. Understanding Risk: Informing Decisions In A Democratic Society (US National Research Council, 1996).

38. Reames, T. G. A community-based approach to low-income residential energy efficiency participation barriers. Local Environ. 21, 1449-1466 (2016). A study exploring a community-based approach to implementing the Weatherization Assistance Program in a low-income, African American urban community

39. Bouzarovski, S. \& Petrova, S. A global perspective on domestic energy deprivation: Overcoming the energy poverty-fuel poverty binary. Energy Res. Soc. Sci. 10, 31-40 (2015).

A study offering an integrated conceptual framework for the research and amelioration of energy deprivation.

40. Hall, S. M., Hards, S. \& Bulkeley, H. New approaches to energy: Equity, justice and vulnerability: Introduction to the special issue. Local Environ. 18, 413-421 (2013).

41. Harrison, C. \& Popke, J. "Because you got to have heat": the networked assemblage of energy poverty in Eastern North Carolina. Ann. Am. Assoc. Geogr. 101, 949-961 (2011).

Suggests energy poverty is best viewed as a geographical assemblage of networked materialities and socioeconomic relationships

42. Bednar, D. J., Reames, T. G. \& Keoleian, G. A. The intersection of energy and justice: Modeling the spatial, racial/ethnic and socioeconomic patterns of urban residential heating consumption and efficiency in Detroit, Michigan. Energy Build. 143, 25-34 (2017).

Provides evidence that supports energy efficiency assistance targeting that recognizes the significant role of race, ethnicity, place and class in energy poverty.

43. Reames, T. G. Targeting energy justice: Exploring spatial, racial/ethnic and socioeconomic disparities in urban residential heating energy efficiency. Energy Policy 97, 549-558 (2016).

44. Jessel, S. G. \& Hernández, D. Energy, poverty, and health in a changing climate: A conceptual review of an emerging literature. Front. Public Health 7 , 357 (2019).

A comprehensive review highlighting the relationship between energy, disproportionate burdens borne by vulnerable populations and health towards adequately meeting household energy needs.

45. Nowak, S., Molina, M., Kushler, M. Recent Developments in Energy Efficiency Evaluation, Measurement, and Verification Report U1712 (American Council for an Energy-Efficient Economy, 2017).

46. Jenkins, K., McCauley, D., Heffron, R., Stephan, H. \& Rehner, R. Energy justice: a conceptual review. Energy Res. Soc. Sci. 11, 174-182 (2016).

47. Sovacool, B. K., Heffron, R. J., McCauley, D. \& Goldthau, A. Energy decisions reframed as justice and ethical concerns. Nat. Ener. 1, 16024 (2016).

48. Agyeman, J., Schlosberg, D., Craven, L. \& Matthews, C. Trends and directions in environmental justice: from inequity to everyday life, community, and just sustainabilities. Annu. Rev. Environ. Resour. 41, 321-340 (2016).

\section{Competing interests}

The authors declare no competing interests.

\section{Additional information}

Correspondence should be addressed to D.J.B.

Reprints and permissions information is available at www.nature.com/reprints. Publisher's note Springer Nature remains neutral with regard to jurisdictional claims in published maps and institutional affiliations.

(c) Springer Nature Limited 2020 